Braz. J. vet. Res. anim. Sci.,

São Paulo, v.32, n.2, p.96-100, 1995.

\title{
ALIMENTAÇÃO DE BEZERROS COM EXTRATO HIDROSSOLÚVEL DE SOJA. I. DESENVOLVIMENTO E DIGESTIBILIDADE
}

\author{
FEEDING CALVES WITH HYDROSOLUBLE SOYBEAN EXTRACT. I. PERFORMANCE \\ AND DIGESTIBILITY
}

Sergio Novita ESTEVES ${ }^{1}$; Marilene Del Vuono Camargo PENTEADO²; Enrico Lippi ORTOLANI ${ }^{3}$

\begin{abstract}
RESUMO
O objetivo do trabalho foi avaliar a substituição total do sucedâneo lácteo à base de proteína de leite (SL) por extrato hidrossolúvel de soja (EHS) na alimentação de bezerros holandeses machos, com idade média inicial de cinco dias. O experimento constou de três tratamentos, conduzidos durante o período de aleitamento dos animais $\left(5^{\circ}\right.$ ao $90^{\circ}$ dia de vida dos animais). O tratamento I consistiu no fornecimento de $\mathrm{SL}$ do $5^{\circ}$ ao $90^{\circ}$ dia de idade dos bezerros. No tratamento Il foi fornecido SL até o $29^{\circ}$ dia de idade e do $30^{\circ}$ ao $90^{\circ}$ dia, EHS. No tratamento IIl foi fornecido EHS a partir do $5^{\circ}$ dia de idade. Após este período, os bezerros foram desaleitados e continuaram a receber feno e ração da mesma forma que no periodo de aleitamento, até os 180 dias de idade. No período de aleitamento, os animais do tratamento II apresentaram significativamente $(P<0,05)$ menor consumo de alimentos, menores coeficientes de digestão aparente dos nutrientes e ganho de peso diário inferior ao dos animais do tratamento I. No tratamento III os bezerros apresentaram, com o desenvolver do experimento, perda de peso, sinais de debilidade no estado corpóreo e foram sacrificados.
\end{abstract}

UNITERMOS: Alimentação; Bezerros; Soja; Desmame; Digestibilidade

\section{INTRODUÇÃO}

Um dos grandes problemas no sistema intensivo da criação de bezerros é o alto custo da alimentação nos primeiros três meses de vida, quando estes são lactentes.

Dentre os alimentos mais procurados para a elaboração do substituto do leite, destaca-se a soja, por conter alto teor de proteina e composição de aminoácidos relativamente bem balanceada (PORTER ${ }^{15}, 1969$ ).

No que diz respeito à quantidade de substituição do leite integral por proteína de soja, ROY et al. ${ }^{16}$ (1977) observaram que quantidades superiores a $30 \%$ podem trazer transtornos à saúde animal, enquanto MORRILL et al. ${ }^{12}$ (1971) concluíram que se pode substituir $22 \%$, mas não $44 \%$ da proteína total por concentrado protéico de soja, sem alterar o ganho de peso e as funções orgânicas dos bezerros. Já a substituição de 50 a $88 \%$ realizada por NITSAN et al. ${ }^{13}$ (1972) forneceu ganhos de peso entre 20 e $30 \%$ menores.
O uso de substitutos lácteos contendo proteína de soja, a partir da primeira semana de vida (SILVA ${ }^{17}, 1984$; DAWSON et al. $^{4}, 1988$ ) ou a partir da $4^{\text {a }}$ semana (GUILHOTEAU et al. ${ }^{8}$, 1986; KHORASANI et al. ${ }^{10}$, 1989), resultou em menores ganhos de peso médio diário dos animais. Conforme TIESENHAUSEN et al. ${ }^{21}$ (1978), o leite de vaca deve ser substituído gradativamente pelo "leite de soja" a partir do $15^{\circ}$ dia de vida dos animais. Da mesma forma, EZEQUIEL et al. ${ }^{6}$ (1988) verificaram diminuição no ganho de peso dos animais, tanto na idade de desmama quanto ao final do experimento aos 116 dias de idade.

Este trabalho teve por objetivo estudar o desenvolvimento de bezerros alimentados com sucedâneos lácteos contendo proteína originária do leite ou proteína de soja, a partir da primeira ou da quarta semana de vida dos bezerros, durante o período de aleitamento e pós-aleitamento.

1 - Médico Veterinário - EMBRAPA/ Unidade de Execução de Pesquisa de Âmbito Estadual, São Carlos, SP
2 - Professor Titular - Faculdade de Ciências Farmacêuticas da USP-SP

3 - Professor Doutor - Faculdade de Medicina Veterinária e Zootecnia da USP-SP 


\section{MATERIAL E MÉTODO}

O experimento foi conduzido no Hospital Veterinário (HOVET) da Faculdade de Medicina Veterinária e Zootecnia da Universidade de São Paulo, no período de abril a novembro de 1987. Foram utilizados 7 bezerros holandeses machos, por tratamento, de 4 a 6 dias de idade, provenientes de uma fazenda produtora de leite tipo "B", no município de Santa Isabel, SP, e identificados numericamente. No dia seguinte, os animais foram pesados e distribuídos casualmente entre os tratamentos e mantidos em baias individuais, com o piso recoberto com cama de maravalha.

O experimento constou de três tratamentos, os quais foram conduzidos durante o período de aleitamento artificial dos animais, do $5^{\circ}$ ao $90^{\circ}$ dia de vida: tratamento I - Sucedâneo lácteo comercial (SL) do $5^{\circ}$ ao $90^{\circ}$ dia; tratamento II - SL do $5^{\circ}$ ao $29^{\circ}$ dia e extrato hidrossolúvel de soja (EHS) do $30^{\circ}$ ao $90^{\circ}$ dia e tratamento III - EHS a partir do $5^{\circ}$ dia.

No periodo de aleitamento, os animais receberam 2 litros de leite pela manhã e 2 à tarde, no balde e de acordo com o tratamento. Desde o início do tratamento, os animais tiveram à disposição feno de "coast-cross" à vontade, ração peletizada comercial, própria para bezerros, em quantidade máxima de $1,0 \mathrm{~kg} /$ dia e água à vontade. No período posterior à desmama, o qual compreendeu do $91^{\circ}$ dia ao $180^{\circ}$ dia de vida dos animais, estes continuaram a receber o feno e a ração da mesma forma que no período de aleitamento.

O SL utilizado neste experimento foi fornecido pela Brasway $\mathrm{S} / \mathrm{A}$, sendo a única fonte de proteína originária do leite. O SL foi preparado diariamente, na proporção de 200 gramas de SL para 2 litros de água $\left(37^{\circ} \mathrm{C}\right)$, no momento de ser oferecido aos animais, às 08 e às 16 horas.

Para o preparo do EHS, utilizou-se o grão de soja moído e misturado em água, na proporção de $1 \mathrm{~kg}$ de grão de soja integral para 6 litros de água e colocado em autoclave a $120^{\circ} \mathrm{C}$ por 20 minutos. A seguir coava-se a mistura, separando a parte líquida (EHS) da sólida (torta), e completava-se a parte líquida com água morna para se manter uma proporção de 1:10. O EHS foi preparado a cada 48 horas e mantido em câmara fria a $4^{\circ} \mathrm{C}$. Quando fornecido aos animais, às $8 \mathrm{e}$ às 16 horas, o EHS era aquecido a $37^{\circ} \mathrm{C}$. A composição química dos sucedâneos está demonstrada na Tab. 1.

Os bezerros foram pesados individualmente, pela manhã e antes da alimentação, do início ao fim do experimento com intervalos de quinze dias.

No final dos períodos de aleitamento e de pós-aleitamento, os bezerros foram colocados em gaiolas metabólicas e utilizou- se o método do óxido crômico para determinação da digestibilidade. Durante um período de seis dias, foram colhidas amostras dos alimentos oferecidos, das sobras, fezes e urina.

As determinações de matéria seca, proteína bruta, fibra detergente neutra e energia bruta foram feitas de acordo com as técnicas descritas por SILVA ${ }^{18}$ (1981). As determinações de óxido crômico nas fezes foram feitas pelo método descrito por KIMURA; MULLER"11 (1957), e o cálculo da produção fecal, conforme $\mathrm{CHURCH}^{2}$ (1974). A determinação do fator inibidor da tripsina foi realizada pelo método descrito por KAKADE et al. ${ }^{9}$ (1974) e da atividade hemaglutinante, conforme FIGUEIROA (1984).

Os resultados foram examinados por análise de variância, e as médias, comparadas pelo teste de Fisher, tendo sido utilizada a técnica de Análise Univariada de Perfis de Médias (SINGER; ANDRADE ${ }^{19}, 1986$ ).

TABELA 1

Composição química dos substitutos lácteos hidratados. São Paulo, abril a novembro de 1987

\begin{tabular}{lcc}
\hline Ingredientes & SL & EHS \\
\hline Extrato seco total (\%) & 8,38 & 3,11 \\
Proteina Bruta (\%) & 2,05 & 1,39 \\
Matéria Mineral (\%) & 0,70 & 0,25 \\
Energia Bruta (cal/g) & 307,90 & 15,32 \\
Inibidor da Tripsina (U.I.T./mg) & - & 1,2 a 3,3 \\
Atividade aglutinante & - & $1: 5,7$ \\
\hline
\end{tabular}

$\mathrm{SL}=$ Sucedâneo Lácteo Comercial

EHS $=$ Extrato Hidrossolúvel de Soja

\section{RESULTADOS E DISCUSSÃO}

O EHS apresentou teor muito baixo de fator inibidor da tripsina, entre 1,22 e 3,38 U.I.T./mg, e atividade hemaglutinante de $1: 5,7$, enquanto no EHS que não sofreu aquecimento foram, respectivamente, 43,6 U.I.T./mg e 1:816, indicando que o tratamento térmico $\left(120^{\circ} \mathrm{C} / 20\right.$ minutos) foi suficiente para inativar a maior parte desses fatores antinutricionais.

O consumo de feno de "coast-cross" pelos animais não diferiu entre si, sendo no final do período de aleitamento de 477 e $353 \mathrm{~g} /$ dia, e no final do período pós-aleitamento de 1762 e $1605 \mathrm{~g} /$ dia, respectivamente para os tratamentos I e II. Porém, sempre se observou consumo superior de feno, apesar de não significativo, nos animais que 
receberam SL, em relação aos que receberam EHS, principalmente no período de aleitamento. Comportamento semelhante foi obtido por EZEQUIEL et al. ${ }^{5}$ (1987), quando do fornecimento de dieta líquida contendo $20 \%$ de leite de soja e $80 \%$ de leite de vaca.

No final do período de aleitamento, houve consumo total médio significativamente maior $(\mathrm{P}<0,05)$ de matéria seca (MS), proteína $(\mathrm{PB})$ e energia bruta $(\mathrm{EB})$ para os animais que ingeriram SL (Tab. 2). Aliados ao menor conteúdo de matéria seca, proteína e energia do EHS, esses resultados sugerem que o EHS exerceu efeito depressor na ingestão total de alimentos. As conversões alimentares não apresentaram diferença significativa $(\mathrm{P}>0,05)$ entre os bezerros dos tratamentos I e II, tanto no período de aleitamento quanto no pós-aleitamento.

A análise dos pesos dos animais demonstrou que no final do período de aleitamento, aos 90 dias de idade, os bezerros que ingeriram o SL apresentaram-se significaticamente mais pesados $(\mathrm{P}<0,05)$ do que os animais que foram alimentados com EHS $(75,7 \mathrm{~kg} \times 60,9 \mathrm{~kg})$, o mesmo ocorrendo no final do experimento aos 180 dias de idade $(130,5 \mathrm{~kg} \mathrm{x} 113,8 \mathrm{~kg})$. A análise do ganho de peso médio diário, realizada no período de aleitamento, após a introdução do EHS na dieta, detectou diferença significativa ( $\mathrm{P}<0,05)$ entre os tratamentos I e II, que foram de $0,552 \mathrm{~kg} \mathrm{e} 0,311 \mathrm{~kg}$, respectivamente. No período pós-aleitamento, o ganho de peso médio diário não diferiu entre os tratamentos, e foram de $0,608 \mathrm{~kg}$ e $0,588 \mathrm{~kg}$, respectivamente. AKINIELE; HARSHBARGER ${ }^{1}$ (1983) e

TABELA 2

Consumo total médio de alimentos, no final do período de aleitamento e pós-aleitamento. São Paulo, abril a novembro de 1987.

\begin{tabular}{lcc}
\hline Variável & Tratamento I & Tratamento II \\
\hline \multicolumn{3}{c}{ Período de Aleitamento } \\
\hline MS - total $(\mathrm{kg} / \mathrm{an} / \mathrm{dia})$ & $1,706^{*}$ & 1,371 \\
$\mathrm{~PB}-$ total $(\mathrm{kg} / \mathrm{an} / \mathrm{dia})$ & $0,350^{*}$ & 0,273 \\
$\mathrm{~EB}-$ total (Mcal $/ \mathrm{dia})$ & $7,578^{*}$ & 5,818 \\
Conversão alimentar (1) & 3,16 & 3,48 \\
\hline
\end{tabular}

\begin{tabular}{lcc}
\hline \multicolumn{3}{c}{ Período de Pós-Aleitamento } \\
\hline MS - total (kg/an/dia) & 2,664 & 2,508 \\
PB - total (kg/an/dia) & 0,235 & 0,228 \\
EB - total (Mcal/dia) & 12,443 & 11,704 \\
Conversão alimentar (1) & 4,65 & 4,42 \\
\hline
\end{tabular}

* significante em nível de $5 \%$ de probabilidade

(1) $\mathrm{Kg}$ MS ingerida/kg de ganho de peso vivo

MS = Matéria Seca

$\mathrm{PB}=$ Proteína Bruta

$\mathrm{EB}=$ Energia Bruta
EZEQUIEL ${ }^{5}$ (1987) relataram que niveis altos de proteína de soja forneceram crescimento insatisfatório aos bezerros, e estão semelhantes aos obtidos neste experimento.

Os coeficientes de digestão aparente do tratamento II, obtidos no final do período de aleitamento, foram significativamente menores $(\mathbf{P}<0,05)$ para a matéria seca, energia bruta e para a proteína bruta $(P<0,10)$, demonstrando que os animais que ingeriram o EHS utilizaram menos eficientemente a dieta (Tab. 3). Esses resultados são semelhantes aos obtidos por ROY et al. ${ }^{16}$ (1977); SILVA $^{17}$ (1984) e DAWSON et al. ${ }^{4}$ (1988) e parcialmente explicam o menor ganho de peso dos animais que ingeriram o EHS, uma vez que consumiram quantidades significativamente inferiores de proteína e energia, com menores coeficientes de digestão. Esses fatos podem ser atribuídos a várias causas, incluindo o impedimento de formação do coágulo no abomaso (ROY et al. ${ }^{16}$, 1977), redução das secreções proteolíticas no trato digestivo (WILLIAMS et al. ${ }^{22}$, 1976), presença de fatores inibidores da tripsina (COLVIN; RAMSEY ${ }^{3}$, 1968) e também por alterações no fluxo intestinal (PEDERSEN; SISSONS ${ }^{14}$, 1984). No período de aleitamento os bezerros que ingeriram SL retiveram significativamente $(\mathrm{P}<0,05)$ maior quantidade de nitrogênio $(24,22 \mathrm{~g} / \mathrm{dia})$ do que os animais alimentados com EHS (17,52 g/dia).

TABELA 3

Coeficientes de digestão aparente da matéria seca(MS), proteína bruta (PB), fibra detergente neutra (FDN) e energia bruta (EB), entre os tratamentos I II durante os períodos experimentais. São Paulo, abril a novembro de 1987.

\begin{tabular}{llll}
\hline Variável & \multicolumn{1}{c}{ Período } & Tratamento I & Tratamento II \\
\hline$\%$ MS & aleitamento & $57,52^{*}$ & 48,38 \\
& pós-aleitamento & 46,15 & 44,53 \\
\hline$\%$ PB & aleitamento & $67,48^{* *}$ & 61,19 \\
& pós-aleitamento & 40,89 & 39,91 \\
\hline \multirow{2}{*}{ FDN } & aleitamento & 21,39 & 17,78 \\
& pós-aleitamento & 37,60 & 34,87 \\
\hline \% EB & aleitamento & $55,57^{*}$ & 42,88 \\
& pós-aleitamento & 45,30 & 43,86 \\
\hline
\end{tabular}

* Significante em nível de $5 \%$ de probabilidade

** Significante em nível de $10 \%$ de probabilidade

No final do período pós-desmama, não se verificou diferença significativa nos coeficientes de digestão aparente e no balanço de nitrogênio entre os tratamentos I e II, ou seja, suprimindo-se o EHS da dieta cessaram-se os efeitos adversos na digestibilidade. 
Os bezerros do tratamento III, após um ou dois dias de aleitamento, apresentaram dificuldade em aceitar o EHS no balde, que foi portanto oferecido através da mamadeira, não se verificando diminuição no consumo desta dieta líquida. SMITH et al. ${ }^{20}(1970)$, em experimento semelhante, verificaram que os bezerros foram relutantes ou até rejeitaram o aleitamento com farinha de soja após duas ou três alimentações. Com a ingestão de EHS, os animais apresentaram diarréia e sinais de fraqueza, apatia e dificuldade locomotora, sendo então sacrificados por eletrocução. Estes animais perderam em média 540 gramas por dia, até a data do sacrifício, que foi em média 12 dias após o início do experimento. Essa perda de peso pode ser creditada ao baixo conteúdo de proteína e energia do EHS em relação ao SL. Estes resultados concordam com os obtidos por SILVA ${ }^{17}$ (1984) e EZEQUIEL et al. ${ }^{5}$ (1987).

\section{CONCLUSÕES}

No período de aleitamento, a substituição total do SL (tratamento I) por EHS (tratamento II), a partir do $30^{\circ}$ dia de vida, resultou numa diminuição significativa no ganho de peso dos bezerros. Este menor desenvolvimento corporal está relacionado à diminuição significativa no consumo total de alimentos, nos coeficientes de digestão aparente da matéria seca, proteína e energia dos animais que ingeriram o EHS. Após a desmama, os ganhos médios diários de peso e os coeficientes de digestão aparente não apresentaram diferença significativa entre os bezerros de ambos os tratamentos.

No entanto, os pesos finais aos 180 dias de idade dos animais que ingeriram o EHS foram significativamente menores que aqueles que receberam o SL.

O fornecimento do EHS aos bezerros, a partir do $5^{\circ}$ dia de idade (tratamento III), causou diarréia e perda de peso.

Esses resultados sugerem que não se deve oferecer o extrato hidrossolúvel de soja a bezerros recém-nascidos, e que, caso se deseje promover um rápido desenvolvimento corporal, deve-se optar pelo oferecimento de sucedâneo lácteo de boa qualidade.

\section{SUMMARY}

The aim of this investigation was to study the total replacement of powder milk protein (SL) for hydrosoluble soybean extract (EHS) in feeding 5-day-old Holstein male calves. The experiment was carried out using 3 treatment throughout the period of milk intake ( 5 to 90 days of life). In treatment I, SL was supplied from the $5^{\text {th }}$ to $90^{\text {th }}$ day of life. In treatment II, SL was supplied until the $29^{\text {th }}$ day, and, from the $30^{\text {th }}$ to $90^{\text {th }}$ day, EHS was supplied. In treatment III, EHS was supplied from the $5^{\text {th }}$ day of life. After this period the calves were weaned and received the same hay and concentrate feed as in the milk intake period, up to 180 days. During the milk intake period, the animals of treatment II, showed in average lower food intake, decreased daily weight gain and poorer digestibility of nutrients than animals from treatment $\mathrm{I}(\mathrm{P}<0.05)$. In the post-weaning period food intake and average daily gain were similar. Calves of treatment III lost weight throughout the experiment, showed very weak body condition and were sacrified.

UNITERMS: Feeding; Calves; Soybeans; Weaning; Digestibility

\section{REFERÊNCIAS BIBLIOGRÁFICAS}

1-AKINYELE, I.O.; HARSHBARGER, K.E. Performance of young calves fed soybean protein replacer. Journal of Dairy Science, v.66, n.4, p.825-32, 1983.

2-CHURCH, D.C.Fisiología digestiva y nutrición de los rumiantes. Zaragoza, Acribia, 1974. v.1, p.163-7.

3-COLVIN, B.M.; RAMSEY,H.A. Soy flour in milk replacer for young calves. Journal of Dairy Science, v.51, n.6, p.898904, 1968.

4-DAWSON, D.P.; MORRILL, J.L.; REDDY, P.G.; MINOCHA, H.C. Soy protein concentrate and heated soy flours as protein sources in milk replacers for preruminant calves. Journal of Dairy Science, v.71, n.5, p.1301-9, 1988.

5-EZEQUIEL,J.M.B.;BARIANI,A.F.;ARAÚJO,W.A.Efeitos de níveis de substituição do leite integral de vaca por leite de soja durante e após o desaleitamento de bezerros da raça Jersey. Zootecnia, Nova Odessa, v.25, n.2, p. I15-27, 1987.

6-EZEQUIEL, J.M.B.; HERLING, V.R.; ARAÚJO, W.A. Digestibilidade de rações fornecidas a bezerros Jersey desaleitados precocemente recebendo leite de soja. Revista da Sociedade Brasileira de Zootecnia, Viçosa, v.17, n.4, p.372-6, 1988. 
ESTEVES. S.N.; PENTEADO, M.V.C.; ORTOLANI, E.L. Alimentaçāo de bezerros com extrato hidrossolúvel de soja. I. desenvolvimento e digestibilidade. Braz. J. vet. Res. anim. Sci., São Paulo, v.32, n.2, p.96-100, 1995.

7-FIGUEIROA, M.O.R.; MANCINI FILHO, J.; LAJOLO, F.M. Ação antinutricional das fito-hemaglutininas de Phaseolus vulgaris I. Archivos Latinoamericanos de Nutrición, Caracas, v.34, n.3, p.488-99, 1984.

8-GU1LHOTEAU, P.; TOULLEC, R.; GRONGNET, J.F. Digestion of milk fish and soybean protein in the preruminant calf: flow of digesta, apparent digestibility at the end of the ileum and amino acid composition of ileal digesta. British Journal of Nutrition, v.55, n.3, p.571-92, 1986.

9-KAKADE, M.L.;RACKIS, J.J.; McGHEE, J.E.; PUSKI,G. Determination of trypsin inhibitor of soy products. A collaborative analysis of an improved procedure. Cereal Chemistry, St. Paul, v.51, n.3, p.376-82,1974.

10-KHORASANI, G.R.; OZIMEC, L.; SAUER, W.C.; KENNELLY, J.J. Substitution of milk protein with isolated soy protein calf milk replacers. Journal of Animal Science, v.67, n.6, p. $1634-41,1989$

11-KIMURA, F.T.; MILLER, J.L. Improved determination of chromic oxid in cow feed and faeces.Journal of Agricultural and Food Chemistry, v.5, n.3, p.216-7, 1957.

12-MORRILL,J.L.; MELTON, S.L.; DAYTON, A.D.; GUY, E.J.; PALLANSCH, M.J. Evaluation of milk replacers containing a soy protein concentrate and high whey. Journal of Dairy Science, v.54, n.7, p.1060-3, 1971.

13-NITSAN, Z.R.; VOLCANI, R.; HASDAI, A.; GORDIN, $S$. Soybean protein substitute for milk protein in milk replacers for suckling calves. Journal of Dairy Science, v.55, n.6, p.811-21, 1972.

14-PEDERSEN, H.E.; SISSONS, J.W. Effect of antigenic soybean protein on the physiology and morphology of the gut in the preruminant calf. Canadian Journal of Animal Science, v.64, p.183-4, 1984. (Supplement 1).

15-PORTER, J.W.G. Digestion in the preruminant animal. Proceedings of the Nutrition Society, v.28, n.1, p.115-21, 1969.
16-ROY, J.H.B.; STOBO, I.J.F.; SHOTTON, S.M.; GANDERTON, P.; GILLIES, C.M. The nutritive value of nonmilk proteins for the preruminant calf. The effect of replacement of milk protein by soybean flour or fish-protein concentrate. British Journal of Nutrition, v.38, p.167-87, 1977.

17-SILVA, A.G.Factors affecting utilization of soybean proteins included in milk replacers for young calves. East Lansing, 1984. Tese (Doutorado) - Michigan State University.

18-SILVA, D.J.Análise de alimentos(métodos químicos e biológicos). Viçosa, UFV/Impr. Univ., 1981. p.166.

19-SINGER, J.M.; ANDRADE, D.F. Análise de dados longitudinais. Campinas, IMECC-UNICAMP, 1986. p.106.

20-SMITH, R.H.; HILL, W.B.; SISSONS, J.W. Effect of diets containing soy products on the passage of digesta through the alimentary tract of the preruminant calf. Proceedings of the Nutrition Society, v.29, n.1, p.2A, 1970.

21-TIESENHAUSEN, I.M.E.V.; SANTOS, E.; DUARTE, G.S.; CHITARRA, A.B.; ALMEIDA, W. Substituição do leite de vaca pelo leite de soja no desmame precoce de bezerros holandeses. In: REUNIÃO DA SOCIEDADE BRASILEIRA DE ZOOTECNIA, 15; 1978. Belém.Anais. Belém, Sociedade Brasileira de Zootecnia, 1978. p.155-6.

22-WILLIAMS, V.J.; ROY, J.H.B.; GILLIES, C.M. Milk substitute diet composition and abomasal secretion in the calf. British Journal of Nutrition, v.36, n.3, p.317-35, 1976.
Recebido para publicação em 07/05/94 Aprovado para publicação em 02/11/94 